\section{Vitamin E did not reduce myocardial infarction, death, or stroke in adults at high risk for cardiovascular events}

The Heart Outcomes Prevention Evaluation Study Investigators. Vitamin E supplementation and cardiovascular events in high-risk patients. N Engl J Med 2000 Jan 20;342:154-60.

\author{
QUESTION: In adults who have a high risk for cardiovascular events, do vitamin E \\ supplements improve cardiovascular outcomes?
}

Sources of funding: Medical Research

Council of Canada; Natural Source Vitamin E Association; Negma;

Hoechst-Marion Roussel; AstraZeneca; King Pharmaceuticals, Heart and Stroke Foundation of Ontario

For correspondence: Dr S Yusuf, Canadian Cardiovascular Collaboration Project Office, Hamilton General Hospital, 237 Barton Street East, Hamilton, Ontario L8L 2X2, Canada.

\section{Design}

Randomised \{allocation concealed $*\} \uparrow$, blinded \{patients, clinicians, and outcome assessors $\} \neq$,* placebo controlled trial with a $2 \times 2$ factorial design and a mean follow up of 4.5 years (Heart Outcomes Prevention Evaluation [HOPE] study).

\section{Setting}

$\{161$ centers in North America, 76 in 14 western European countries, and 30 in Argentina and Brazil. $\}+$

\section{Patients}

9541 patients (mean age 66 y, $73 \%$ men) who were $\{\geq 55$ years of age and had a history of coronary artery disease, stroke, peripheral vascular disease, or diabetes and $\geq 1$ other cardiovascular disease risk factor. Exclusion criteria were heart failure, ejection fraction $<0.4$, use of an angiotensin converting enzyme inhibitor or vitamin $\mathrm{E}$, uncontrolled hypertension, nephropathy, or myocardial infarction (MI) or stroke in the previous 4 weeks. Follow up was $99.9 \%$.

\section{Intervention}

Patients were allocated to 1 of 4 groups: ramipril and vitamin E; ramipril and placebo; vitamin $\mathrm{E}$ and placebo; or placebo alone. 4761 adults were assigned to vitamin $\mathrm{E}$ and 4780 to placebo. Doses were $10 \mathrm{mg}$ /day of ramipril and $400 \mathrm{IU} /$ day of vitamin $\mathrm{E}$.

\section{Main outcome measures}

Combined outcome of MI, stroke, or death from cardiovascular causes. Secondary outcomes included all cause mortality.

\section{Main results}

Vitamin E and placebo groups did not differ for any outcome (table).

\section{Conclusion}

In adults at high risk for cardiovascular events, vitamin E, $400 \mathrm{IU} /$ day, did not reduce myocardial infarction, stroke, or death.

*See glossary.

†The HOPE Study Investigators. Can J Cardiol 1996;12:127-37.

$\ddagger$ The Heart Outcomes Prevention Evaluation Study Investigators. N Engl J Med 2000;342:145-53.
Vitamin Ev placebo for adults at high risk for cardiovascular events\$

\begin{tabular}{lcccc}
$\begin{array}{l}\text { Outcomes at mean } \\
\text { 4.5 years }\end{array}$ & Vitamin E & Placebo & RRI $(95 \%$ Cl) & NNH \\
$\begin{array}{l}\text { Myocardial infarction, stroke, } \\
\text { or cardiovascular mortality }\end{array}$ & $16 \%$ & $15 \%$ & $5 \%(-4$ to 15$)$ & Not significant \\
\hline Cardiovascular mortality & $7.1 \%$ & $6.9 \%$ & $5 \%(-10$ to 21$)$ & Not significant \\
\hline Myocardial infarction & $11.2 \%$ & $11.0 \%$ & $2 \%(-9$ to 14$)$ & Not significant \\
\hline Stroke & $4.4 \%$ & $3.8 \%$ & $17 \%(-4$ to 42$)$ & Not significant \\
\hline All cause mortality & $11 \%$ & $11 \%$ & $0 \%(-11$ to 12$)$ & Not significant \\
\hline §Abbreviations defined in glossary; $\mathrm{RRI}, \mathrm{NNH}$, and $\mathrm{Cl}$ calculated from data in article. &
\end{tabular}

\section{COMMENTARY}

Research linking low density lipoprotein (LDL) oxidation with atherogenesis led to expectations that antioxidant supplements would reduce cardiovascular disease. The HOPE study is yet another large, randomised, controlled trial that fails to show any cardiovascular benefit from antioxidants. ${ }^{12}$ Although a single tertiary prevention trial found that vitamin E reduced the risk for non-fatal MIs, results were challenged because supplements were taken for a relatively short time, treatment groups were not comparable at baseline, and cardiovascular mortality risk was unaffected. ${ }^{3}$

Why was vitamin E not effective for the high risk patients in the HOPE study? Healthy adults receiving 400 IUs of vitamin $\mathrm{E}$ can substantially increase plasma antioxidant concentrations and inhibit LDL oxidation. However, patients with existing disease may need higher doses because of increased oxidative stress. Another possibility is that longer term antioxidant treatment is required, although an observational study found that 2 years of supplemental intake was sufficient to lower the risk for coronary disease. ${ }^{1}$ Ongoing trials are also looking at combinations of antioxidants, which may be more effective than a single supplement. ${ }^{1}$ Furthermore, several of these trials address potential sex differences in outcomes by enrolling only women; women made up just $27 \%$ of the HOPE study participants.

How should antioxidants be used in practice? Vitamin $\mathrm{E}$ is clearly safe, but no conclusive evidence exists to show that supplements reduce cardiovascular disease. While awaiting results from ongoing trials, providers should encourage patients to eat fruits and vegetables and to continue with proven strategies to prevent cardiovacular disease.

Richard M Hoffman, MD, MPH Albuquerque Veterans Affairs Medical Center Albuquerque, New Mexico, USA

1 Jha P, Flather M, Lonn E, et al. The antioxidant vitamins and cardiovascular disease. A critical review of epidemiologic and clinical trial data. Ann Intern Med 1995;123:860-72.

2 GISSI-Prevenzione Investigators. Dietary supplementation with n-3 polyunsaturated fatty acids and vitamin $\mathrm{E}$ after myocardial infarction: results of the GISSI-Prevenzione trial. Gruppo Italiano per lo Studio della Sopravvivenza nell'Infarto miocardico. Lancet 1999;354:447-55.

3 Stephens NG, Parsons A, Schofield PM, et al. Randomised controlled trial of vitamin E in patients with coronary disease: Cambridge Heart Antioxidant Study (CHAOS). Lancet 1996;347:781-6. 